\title{
Effect of trabectedin on the QT interval in patients with advanced solid tumor malignancies
}

\author{
R. Thertulien · G. M. Manikhas $\cdot$ L. Y. Dirix $\cdot$ \\ J. B. Vermorken · K. Park · M. M. Jain · J. J. Jiao • \\ J. Natarajan $\cdot$ T. Parekh $\cdot$ P. Zannikos $\cdot$ A. P. Staddon
}

Received: 17 March 2011 / Accepted: 15 June 2011 / Published online: 8 July 2011

(C) The Author(s) 2011. This article is published with open access at Springerlink.com

\begin{abstract}
Purpose The primary objective of this study was to access the potential effects of trabectedin on the QT/QTc interval in patients with locally advanced or metastatic solid tumors.

Methods Patients $(n=75)$ who had received $\leq 3$ previous lines of chemotherapy and had either relapsed or had progressive disease were enrolled. Patients were administered 3-h intravenous infusions of placebo (saline) on day 1 and trabectedin $\left(1.3 \mathrm{mg} / \mathrm{m}^{2}\right)$ on day 2 . Time-matched serial triplicate ECG recordings and pharmacokinetic blood samples were collected over $24 \mathrm{~h}$ on both days. Heart rate corrected
\end{abstract}

Registration: The study is registered at Clinicaltrials.gov (NCT00786838).

Previous presentations: An abstract based on data from this study was accepted for publication only, at the Annual meeting of the American Society of Clinical Oncology, held from June 4-8, 2010 at Chicago, Illinois.

\section{R. Thertulien ( $\square)$}

Cancer Centers of North Carolina-Asheville,

20 Medical Park Drive, Asheville, NC 28803, USA

e-mail: raymond.thertulien@usoncology.com

G. M. Manikhas

City Clinical Oncology Dispensary, St. Petersburg, Russia

L. Y. Dirix

AZ Sint-Augustinus, Oncologisch Centrum, Wilrijk, Belgium

J. B. Vermorken

Universitair Ziekenhuis Antwerpen, Edegem, Belgium

K. Park

Samsung Medical Center, Sungkyunkwan University

School of Medicine, Seoul, Korea mean QT intervals and changes from predose baseline in QTc $(\Delta \mathrm{QTc})$ were assessed. The difference in $\Delta \mathrm{QTc}$ between trabectedin and placebo was calculated at each time point $(\Delta \Delta \mathrm{QTc})$.

Results The upper limits of the $90 \%$ confidence interval for $\Delta \Delta \mathrm{QTcF}$ and $\Delta \Delta \mathrm{QTcB}$ at all time points were less than the prespecified noninferiority margin of $10 \mathrm{~ms}$ $(\leq 6.65 \mathrm{~ms}$ ). No patient had a QTc $>500 \mathrm{~ms}$ or a timematched increase from baseline in QTc $>60 \mathrm{~ms}$ at any time point. Regression analyses indicated $\Delta \Delta \mathrm{QTc}$ was poorly correlated with trabectedin concentration. No adverse events suggestive of proarrhythmic potential were reported. Conclusion Trabectedin did not prolong the QTc interval. Safety and pharmacokinetic profiles of trabectedin were similar to that observed in other ovarian and breast cancer studies.

Keywords Anti-tumor $\cdot$ ECG $\cdot$ Malignancies · QTc interval · Trabectedin

M. M. Jain

Ruby Hall Clinic, Pune, India

J. J. Jiao $\cdot$ J. Natarajan $\cdot$ T. Parekh $\cdot$ P. Zannikos Johnson \& Johnson Pharmaceutical Research \& Development, L.L.C., Raritan, NJ, USA
A. P. Staddon
Pennsylvania Oncology Hematology Associates,
Philadelphia, PA, USA 


\section{Introduction}

Trabectedin is a tris, tetrahydroisoquinoline alkaloid originally isolated from the marine ascidian, Ecteinascidia turbinata, and now produced synthetically. It binds to the minor groove of DNA and interacts with proteins of the DNArepair machinery [1], disrupting the cell cycle and inhibiting cell proliferation [2]. Trabectedin is approved in several countries including the European Union (not approved in the United States) for patients with advanced soft tissue sarcoma after treatment failure with anthracycline and ifosfamide. It is also approved in the European Union in combination with pegylated liposomal doxorubicin for the treatment of patients with relapsed, platinum-sensitive ovarian cancer [3].

In a population pharmacokinetic (PK) analysis, trabectedin as a single intravenous (i.v.) infusion for periods of 1 , 3 , and $24 \mathrm{~h}$ showed time-independent and linear PK [4]. Trabectedin is highly bound $(94.2 \%)$ to plasma proteins [5] and undergoes extensive metabolism via the cytochrome P450 system, mainly by the CYP3A4 isoenzyme [6]. The extensive tissue distribution of trabectedin (distribution volume of $>5,000 \mathrm{~L}$ ) accounts for the multi-exponential decline in concentrations in plasma and relatively long terminal half-life of approximately $180 \mathrm{~h} \mathrm{[4].}$

The present study was conducted primarily to assess the potential effects of therapeutic doses of trabectedin on the QT/QTc interval duration in patients with advanced solid tumor malignancies, as recommended in the International Conference of Harmonization (ICH) E14 guidelines. The secondary objectives of this study were to assess the safety and PK of trabectedin and its effect on patient survival.

\section{Patients and methods}

\section{Patients}

Seventy-five male and female patients (age, 18-65 years, inclusive) with locally advanced or metastatic solid tumors who had received not more than 3 lines of systemic chemotherapy or were intolerant to standard chemotherapy were enrolled in the study. Additional inclusion criteria were left ventricular ejection fraction within normal limit in patients previously treated with a cumulative anthracycline dose over $260 \mathrm{mg} / \mathrm{m}^{2}$; supine blood pressure between 90 and $140 \mathrm{mmHg}$ systolic and not more than $90 \mathrm{mmHg}$ diastolic; a 12-lead electrocardiogram (ECG) consistent with normal cardiac conduction and function; Eastern Cooperative Oncology Group (ECOG) performance status of 0-1; and clinical laboratory values within acceptable limits as predefined in the protocol. Patients had to be non-smokers (for at least 6 months before study drug administration) and be able to receive dexamethasone.
Patients treated with more than 3 prior chemotherapy regimens and those with previous exposure to trabectedin, known hypersensitivity to any of the components of the trabectedin (i.v.) formulation or dexamethasone, heart rhythm disturbances, unusual T- and U-wave (if present) morphology, CNS metastasis, cardiac failure, myocardial infarction or cardiomyopathy, additional risk factors for torsade de pointes (e.g., heart failure, electrolyte abnormalities, family history of long QT syndrome) and with any condition likely to interfere with placement of the ECG electrode and electrical conduction were excluded from the study. Furthermore, patients at screening receiving medication that prolonged QT interval or who were on CYP3A4 inhibitors or inducers and with current clinically significant other medical illness were excluded. Women who were breastfeeding and those planning to become pregnant during the study were also excluded.

\section{Study design}

This was a single-blind (patients blinded to treatment), multicenter, placebo-controlled, sequential design study. It included a screening period of up to 21 days during which patient eligibility was assessed, followed by a treatment phase of 2 single-dose treatments. On day 1 of the treatment phase, the patients were administered placebo (normal saline, 3-h i.v. infusion), and on day 2 , the patients received trabectedin $\left(1.3 \mathrm{mg} / \mathrm{m}^{2}, 3-\mathrm{h}\right.$ i.v. infusion). Dexamethasone (20 mg or equivalent, i.v.) was administered $30 \mathrm{~min}$ before the i.v. infusions on day 1 and day 2. Granisetron or ondansetron was also administered $30 \mathrm{~min}$ before the i.v. infusions if additional antiemetic therapy was considered necessary. Twelve-lead ECGs were obtained by a GE MAC $^{\circledR} 1200$ resting 12-lead ECG device (General Electric Healthcare) with the capacity for digital signal processing and were extracted by a core ECG laboratory (MDS Pharma Services, Ontario, Canada). Blood samples were collected at prespecified times for the determination of trabectedin concentrations in plasma.

This study was conducted in accordance with the ethical principles originating in the provisions of the World Medical Association Declaration of Helsinki and its amendments concerning medical research in humans and in conformance with all local laws and regulations. Documentation procedures complied with ICH guidelines. Study procedures were designed to ensure adherence to Good Clinical Practices and the Code of Federal Regulations 21 and in compliance with the respective protocols. Written consent was obtained from all patients before performance of any study-related activity. Approval for the study was obtained from an Independent Ethics Committee or Institutional Review Board at each participating investigative site. 
Evaluations

\section{ECG acquisition}

On days 1 and 2, serial ECGs (10-s digital ECGs) were recorded in triplicate (maximum of 2 min between each of the triplicate) at each of the following time points: predose and at 1, 2, 2.75, 4, 6 and $8 \mathrm{~h}$ after the start of the infusion. Electrocardiograms were also collected $24 \mathrm{~h}$ after trabectedin administration on day 2. The predose (baseline) ECG assessments were recorded within $30 \mathrm{~min}$ before the dose of placebo and trabectedin. Patients remained in the comfortable supine position for at least $10 \mathrm{~min}$ preceding and following the ECG tracings. Physical activity, position, external stimulation, and meal ingestion were closely regulated to keep physical activity and emotional excitement to a minimum. Patients were allowed to be ambulatory between ECG assessments.

\section{ECG analysis and interpretation}

The ECG tracings were evaluated by the third-party central ECG laboratory, which was blinded to treatment (i.e., study day) and time. All ECGs were read by a certified cardiologist. The ECGs were measured by digital on-screen calipers, using a semi-automated method (prepositioning of the cursors by the automatic analysis followed by an over-read of each ECG by a cardiologist). To correct for possible effects of heart rate, Fridericia $\left(\mathrm{QTcF}=\mathrm{QT} / \mathrm{RR}^{1 / 3}\right)$ and Bazetts $\left(\mathrm{QTcB}=\mathrm{QT} / \mathrm{RR}^{1 / 2}\right)$ corrections were used as the primary and secondary methods, respectively. The final value for each QTc was the average of three complexes. All recordings, including the waveforms with interval measurements, were digitally stored.

\section{Pharmacokinetic evaluations}

Peripheral venous blood samples for the determination of trabectedin plasma concentrations were collected predose and following placebo (day 1) and trabectedin (day 2) administration. The blood samples were time-matched to the ECG measurements and collected within 5 min after the last ECG tracing of the triplicate ECGs was recorded. Blood samples were collected at $2 \mathrm{~h} 45$ min after dosing with placebo on day 1 to verify the absence of trabectedin (as time required to reach the maximum concentration $\left[t_{\max }\right]$ of trabectedin was observed to be $2-3 \mathrm{~h}$ in previous studies). The concentrations of trabectedin in plasma were determined by a validated liquid chromatography-mass spectrometry/mass spectrometry (LC-MS/ MS) method at the Slotervaart Hospital in Amsterdam, The Netherlands.

\section{Safety evaluations}

Safety evaluations included assessment of treatment-emergent adverse events (TEAEs), clinical laboratory tests, vital signs measurements, and physical examination. All TEAEs were evaluated in terms of intensity, duration, seriousness, and outcome.

\section{Statistical analysis}

\section{Sample size determination}

The intrasubject standard deviation for $\Delta \mathrm{QTcF}$ was assumed to be $10 \mathrm{~ms}$. For a sample size of 52 patients (completers) and assuming the true difference in means equals $5 \mathrm{~ms}$, the probability that the upper limit of the twosided $90 \%$ confidence interval (CI) for the $\Delta \Delta \mathrm{QTc}$ at each time point would fall below $10 \mathrm{~ms}$ was estimated to be $80 \%$. Approximately 60 patients were to be enrolled to ensure that at least 52 evaluable patients completed all required assessments.

\section{Statistical methods}

ECG-related variables were calculated for all patients who received treatment on both days, had predose baseline values for placebo and trabectedin, and had at least one paired postdose value (evaluable analysis set). The primary pharmacodynamic parameter was the difference in the change from predose $(\Delta \mathrm{QT} c)$ at each scheduled time point between trabectedin (day 2) and placebo (day 1). The predose time point on day 2 was also the 24-h time point for day 1 . For each patient, the difference in $\Delta \mathrm{QTc}$ between trabectedin and placebo was calculated at each time point $(\Delta \Delta \mathrm{QTc}=\Delta \mathrm{QTc}$ for trabectedin minus $\Delta \mathrm{QTc}$ for placebo for the patient at the same time point). Mean $\Delta \Delta \mathrm{QTc}$ and the $90 \% \mathrm{CI}$ for $\Delta \Delta \mathrm{QTc}$ were calculated at each time point.

A mixed effect analysis of variance (ANOVA) model was fitted with the $\Delta \mathrm{QTc}$ data as the dependent variable and treatment (trabectedin, placebo), scheduled time point of measurement, and treatment by scheduled time point of measurement interaction as fixed effects and patients as a random effect. Using the estimated least square means and intrasubject variance obtained from this model, 2-sided $90 \%$ CI was calculated for $\Delta \Delta \mathrm{QTc}$ at each scheduled time point. Non-inferiority, defined as the absence of QTc prolongation when compared with placebo, was concluded if at each scheduled time point the upper limit of the two-sided $90 \% \mathrm{CI}$ fell below $10 \mathrm{~ms}$. Mean QTc, $\Delta \mathrm{QTc}$, and $\Delta \Delta \mathrm{QTc}$ were summarized by using descriptive statistics at each time point and by treatment.

Incidence count and percentage of patients with QTc values above the following limits were summarized: QTc 
interval $>450 \mathrm{~ms}$, QTc interval $>480 \mathrm{~ms}$, and QTc interval $>500 \mathrm{~ms}$. Incidence count and percentage of patients with QTc increase from predose $(\Delta \mathrm{QTc})$ for each treatment and time point were summarized for the following categories: QTc interval increase from baseline $>30 \mathrm{~ms}$ and QTc interval increase from baseline $>60 \mathrm{~ms}$. Additional analyses were performed after the QTc results became available to summarize the incidence count and percentage of patients whose QTc values were reduced from baseline by $>30 \mathrm{~ms}$, $>60 \mathrm{~ms}$, and absolute QTc intervals that were $<360$ and $<320 \mathrm{~ms}$.

The intervals RR, PR, and QRS were listed over time for each patient and treatment. For each treatment group and time point of measurement, the data were summarized using descriptive statistics. The number and percentage of patients who experienced PR or QRS interval abnormalities based on the following criteria were summarized by treatment: PR interval >200 ms and QRS interval >120 ms.

\section{Relationship between plasma trabectedin and QT/QTc interval changes}

Analysis using a linear mixed effects model was performed with $\Delta \Delta \mathrm{QTc}$ as dependent variable and trabectedin concentration as a predictor and patients as random effect. The random intercept model was selected as the best fit model, and the predicted value of $\Delta \Delta \mathrm{QTc}$ (along with $90 \% \mathrm{CI}$ ) was estimated at the mean $C_{\max }$ values of trabectedin based on this model.

\section{Morphological analyses of heart rate ECG waveforms}

Mean heart rate (HR) and corresponding changes from baseline were summarized using descriptive statistics by treatment group and time point. T-wave morphology and abnormal U-waves were summarized by treatment group.

\section{Safety evaluations}

Safety analyses were summarized with descriptive statistics, for the treated analysis set that was composed of all patients who received at least 1 dose of study drug or placebo and provided at least one postdose measurement.

\section{Results}

Patient enrollment, demographics, and baseline characteristics

This single-blind study enrolled 75 patients at 20 sites in 7 countries from October 14, 2008 to April 16, 2009. Of the enrolled patients, 72 completed the study, and 3 patients
Table 1 Demographic and baseline characteristics

\begin{tabular}{|c|c|}
\hline & Total $(N=75)$ \\
\hline Age (years), Mean (SD) & $50.1(11.03)$ \\
\hline \multicolumn{2}{|l|}{ Sex, $n(\%)$} \\
\hline Female & $51(68)$ \\
\hline Male & $24(32)$ \\
\hline \multicolumn{2}{|l|}{ Race, $n(\%)$} \\
\hline White & $51(68)$ \\
\hline Asian & $23(31)$ \\
\hline Other & $1(1)$ \\
\hline BMI $\left(\mathrm{kg} / \mathrm{m}^{2}\right)$, mean $(\mathrm{SD})$ & $25.6(5.45)$ \\
\hline $\mathrm{BSA}\left(\mathrm{m}^{2}\right)$, mean $(\mathrm{SD})$ & $1.8(0.22)$ \\
\hline \multicolumn{2}{|c|}{ Baseline ECOG performance status, $n(\%)$} \\
\hline 0 & $31(41)$ \\
\hline 1 & $44(59)$ \\
\hline \multicolumn{2}{|l|}{ Tumor type, $n(\%)$} \\
\hline Sarcoma & $25(33)$ \\
\hline Breast & $11(15)$ \\
\hline Ovarian & $23(31)$ \\
\hline Other & $16(21)$ \\
\hline \multicolumn{2}{|l|}{ Stage of disease, $n(\%)$} \\
\hline II & $8(11)$ \\
\hline III & $15(20)$ \\
\hline IV & $51(68)$ \\
\hline NA & $1(1)$ \\
\hline $\begin{array}{l}\text { Number of site involvement at } \\
\text { baseline, mean (SD) }\end{array}$ & $1.8(1.37)$ \\
\hline $\begin{array}{l}\text { Total no. of patients with previous } \\
\text { chemotherapy, } n(\%)\end{array}$ & $74(99)$ \\
\hline Antineoplastic agents & $74(99)$ \\
\hline All other therapeutic products, $n(\%)$ & $4(5)$ \\
\hline Endocrine therapy & $4(5)$ \\
\hline Antipsoriatics & $3(4)$ \\
\hline Cough and cold preparations & $3(4)$ \\
\hline Antianemic preparation & $2(3)$ \\
\hline $\begin{array}{l}\text { Sex hormones and modulators } \\
\text { of the genital system }\end{array}$ & $1(1)$ \\
\hline
\end{tabular}

BMI body mass index, $B S A$ body surface area, ECOG Eastern Cooperative Oncology Group

died within 30 days after study treatment. All 75 patients were included in the treated analysis set, and 74 patients were included in the evaluable analysis set (one patient who received trabectedin and placebo in the reverse order was not included).

The demographic and baseline characteristics of the enrolled population are given in Table 1 . The most common tumor types were sarcoma (33\%) and ovarian cancer (31\%). Most patients (99\%) had received prior cancer therapy. 
Table 2 Estimated means and confidence intervals of the effect of placebo and trabectedin on the QTcF interval (ms) in patients with advanced solid tumor malignancies treated with a single dose of $1.3 \mathrm{mg} / \mathrm{m}^{2}$ trabectedin (3-h infusion) (evaluable analysis set)

\begin{tabular}{|c|c|c|c|c|c|}
\hline$N$ & $\begin{array}{l}\text { Scheduled } \\
\text { time }\end{array}$ & $\begin{array}{l}\text { Arithmetic } \\
\text { mean trabectedin } \\
\text { concentration } \\
(\mathrm{ng} / \mathrm{ml})\end{array}$ & $\begin{array}{l}\text { Arithmetic } \\
\text { mean }(\mathrm{ms}) \\
(95 \% \mathrm{CI})\end{array}$ & $\begin{array}{l}\text { Arithmetic } \\
\text { mean }(\mathrm{ms}) \\
\text { CFB }(95 \% \mathrm{CI})\end{array}$ & $\begin{array}{l}\text { Placebo-adjusted } \\
\text { LS mean } \\
\text { CFB (ms) }(90 \% \mathrm{CI})\end{array}$ \\
\hline \multicolumn{6}{|c|}{ Placebo (Day 1) } \\
\hline$n=74$ & Predose & - & $\begin{array}{l}406.2 \\
(402.0 ; 410.5)\end{array}$ & - & - \\
\hline$n=74$ & $1 \mathrm{~h}$ & - & $\begin{array}{l}408.0 \\
(403.6 ; 412.3)\end{array}$ & $\begin{array}{l}1.7 \\
(0.1 ; 3.4)\end{array}$ & - \\
\hline$n=74$ & $2 \mathrm{~h}$ & - & $\begin{array}{l}411.4 \\
(406.9 ; 415.9)\end{array}$ & $\begin{array}{l}5.2 \\
(3.2 ; 7.1)\end{array}$ & - \\
\hline$n=74$ & $2 \mathrm{~h} 45 \mathrm{~min}$ & - & $\begin{array}{l}413.4 \\
(409.0 ; 417.9)\end{array}$ & $\begin{array}{l}7.2 \\
(5.3 ; 9.1)\end{array}$ & - \\
\hline$n=74$ & $4 \mathrm{~h}$ & - & $\begin{array}{l}415.9 \\
(411.5 ; 420.3)\end{array}$ & $\begin{array}{l}9.7 \\
(7.3,12.0)\end{array}$ & - \\
\hline$n=74$ & $6 \mathrm{~h}$ & - & $\begin{array}{l}411.5 \\
(407.1 ; 416.0)\end{array}$ & $\begin{array}{l}5.3 \\
(3.1 ; 7.4)\end{array}$ & - \\
\hline$n=73$ & $8 \mathrm{~h}$ & - & $\begin{array}{l}408.9 \\
(404.8 ; 413.1)\end{array}$ & $\begin{array}{l}2.5 \\
(0.3 ; 4.8)\end{array}$ & - \\
\hline$n=74$ & $24 \mathrm{~h}$ & - & $\begin{array}{l}409.8 \\
(405.8 ; 413.8)\end{array}$ & $\begin{array}{l}3.6 \\
(1.2 ; 5.9)\end{array}$ & - \\
\hline \multicolumn{6}{|c|}{ Trabectedin $1.3 \mathrm{mg} / \mathrm{m}^{2}$ (Day 2) } \\
\hline$n=74$ & Predose & - & $\begin{array}{l}409.8 \\
(405.8 ; 413.8)\end{array}$ & - & - \\
\hline$n=74$ & $1 \mathrm{~h}$ & 7.15 & $\begin{array}{l}410.1 \\
(405.8 ; 414.5)\end{array}$ & $\begin{array}{l}0.3 \\
(-1.7 ; 2.4)\end{array}$ & $\begin{array}{l}-1.4 \\
(-3.35 ; 0.51)\end{array}$ \\
\hline$n=74$ & $2 \mathrm{~h}$ & 8.07 & $\begin{array}{l}411.3 \\
(406.9 ; 415.8)\end{array}$ & $\begin{array}{l}1.5 \\
(-0.8 ; 3.8)\end{array}$ & $\begin{array}{l}-3.7 \\
(-5.68 ;-1.63)\end{array}$ \\
\hline$n=72$ & $2 \mathrm{~h} 45 \mathrm{~min}$ & 6.98 & $\begin{array}{l}413.1 \\
(408.5 ; 417.7)\end{array}$ & $\begin{array}{l}2.7 \\
(0.6 ; 4.8)\end{array}$ & $\begin{array}{l}-4.5 \\
(-6.55 ;-2.40)\end{array}$ \\
\hline$n=72$ & $4 \mathrm{~h}$ & 1.70 & $\begin{array}{l}413.8 \\
(409.7 ; 417.9)\end{array}$ & $\begin{array}{l}3.8 \\
(1.5 ; 6.1)\end{array}$ & $\begin{array}{l}-5.8 \\
(-8.19 ;-3.45)\end{array}$ \\
\hline$n=73$ & $6 \mathrm{~h}$ & 0.909 & $\begin{array}{l}411.0 \\
(407.1 ; 414.9)\end{array}$ & $\begin{array}{l}1.0 \\
(-1.3 ; 3.4)\end{array}$ & $\begin{array}{l}-4.2 \\
(-6.26 ;-2.22)\end{array}$ \\
\hline$n=73$ & $8 \mathrm{~h}$ & 0.690 & $\begin{array}{l}410.2 \\
(406.1 ; 414.4)\end{array}$ & $\begin{array}{l}0.3 \\
(-2.3 ; 2.8)\end{array}$ & $\begin{array}{l}-2.3 \\
(-4.82 ; 0.26)\end{array}$ \\
\hline$n=73$ & $24 \mathrm{~h}$ & 0.443 & $\begin{array}{l}403.7 \\
(399.4 ; 408.0)\end{array}$ & $\begin{array}{l}-6.2 \\
(-8.7 ;-3.8)\end{array}$ & $\begin{array}{l}-9.8 \\
(-12.65 ;-6.99)\end{array}$ \\
\hline
\end{tabular}

Sample sizes provided in the table refer to the QTcF results. The descriptive statistical analyses of the trabectedin concentrations included $67-73$ patients at each time point

$C F B$ change from base line, $C I$ confidence interval, $m s$ milliseconds

ECG analysis

\section{$Q T c F$ and $Q T c B$}

As mentioned earlier, for QT interval assessment, Fridericia and Bazetts methods were used to correct for heart rate. The appropriateness of the correction factors was assessed by simple linear regression of QTc versus the RR interval. The results indicate that both correction methods were adequate. The analyses resulted in slopes of $0.101\left(R^{2}=0.12\right)$ and $-0.065\left(R^{2}=0.05\right)$ for Fridericia and Bazetts methods, respectively. The regression analysis of uncorrected QT versus $R R$ resulted in a slope of $0.435\left(R^{2}=0.72\right)$.

The mean baseline (predose) QTcF and QTcB intervals were similar before placebo and trabectedin administration (Tables 2 and 3). The mean QTcF intervals increased during the first $4 \mathrm{~h}$ after the start of either placebo or trabectedin (Table 2). Thereafter, the QTcF intervals declined gradually to approximate predose values at the time of the 8-h ECG assessments. Small changes were also observed in the mean QTcB intervals during $24 \mathrm{~h}$ after the start of the placebo or infusions (Table 3). 
Table 3 Estimated means and confidence intervals of the effect of placebo and trabectedin on the QTcB interval (ms) in patients with advanced solid tumor malignancies treated with a single dose of $1.3 \mathrm{mg} / \mathrm{m}^{2}$ trabectedin (3-h infusion) (evaluable analysis set)

\begin{tabular}{|c|c|c|c|c|c|}
\hline$N$ & $\begin{array}{l}\text { Scheduled } \\
\text { time }\end{array}$ & $\begin{array}{l}\text { Arithmetic } \\
\text { mean trabectedin } \\
\text { concentration } \\
(\mathrm{ng} / \mathrm{ml})\end{array}$ & $\begin{array}{l}\text { Arithmetic } \\
\text { mean }(\mathrm{ms}) \\
(95 \% \mathrm{CI})\end{array}$ & $\begin{array}{l}\text { Arithmetic } \\
\text { Mean CFB (ms) } \\
(95 \% \text { CI) }\end{array}$ & $\begin{array}{l}\text { Placebo-adjusted } \\
\text { LS mean CFB (ms) } \\
(90 \% \text { CI })\end{array}$ \\
\hline \multicolumn{6}{|c|}{ Placebo (Day 1) } \\
\hline$n=74$ & Predose & - & $\begin{array}{l}426.3 \\
(422.3 ; 430.3)\end{array}$ & - & - \\
\hline$n=74$ & $1 \mathrm{~h}$ & - & $\begin{array}{l}425.1 \\
(420.9 ; 429.3)\end{array}$ & $\begin{array}{l}-1.2 \\
(-3.4 ; 1.0)\end{array}$ & - \\
\hline$n=74$ & $2 \mathrm{~h}$ & - & $\begin{array}{l}428.0 \\
(423.4 ; 432.5)\end{array}$ & $\begin{array}{l}1.7 \\
(-0.7 ; 4.0)\end{array}$ & - \\
\hline$n=74$ & $2 \mathrm{~h} 45 \mathrm{~min}$ & - & $\begin{array}{l}430.4 \\
(426.1 ; 434.7)\end{array}$ & $\begin{array}{l}4.1 \\
(1.7 ; 6.4)\end{array}$ & - \\
\hline$n=74$ & $4 \mathrm{~h}$ & - & $\begin{array}{l}435.4 \\
(431.3 ; 439.5)\end{array}$ & $\begin{array}{l}9.1 \\
(6.4 ; 11.8)\end{array}$ & - \\
\hline$n=74$ & $6 \mathrm{~h}$ & - & $\begin{array}{l}435.5 \\
(431.0 ; 440.0)\end{array}$ & $\begin{array}{l}9.2 \\
(6.6 ; 11.7)\end{array}$ & - \\
\hline$n=73$ & $8 \mathrm{~h}$ & - & $\begin{array}{l}433.3 \\
(429.0 ; 437.6)\end{array}$ & $\begin{array}{l}6.7 \\
(4.1 ; 9.4)\end{array}$ & - \\
\hline$n=74$ & $24 \mathrm{~h}$ & - & $\begin{array}{l}426.4 \\
(422.3 ; 430.4)\end{array}$ & $\begin{array}{l}0.1 \\
(-2.3 ; 2.4)\end{array}$ & - \\
\hline \multicolumn{6}{|c|}{ Trabectedin $1.3 \mathrm{mg} / \mathrm{m}^{2}$ (Day 2) } \\
\hline$n=74$ & Predose & - & $\begin{array}{l}426.4 \\
(422.3 ; 430.4)\end{array}$ & - & - \\
\hline$n=74$ & $1 \mathrm{~h}$ & 7.15 & $\begin{array}{l}423.7 \\
(419.6 ; 427.9)\end{array}$ & $\begin{array}{l}-2.6 \\
(-5.4 ; 0.1)\end{array}$ & $\begin{array}{l}-1.4 \\
(-4.04 ; 1.23)\end{array}$ \\
\hline$n=74$ & $2 \mathrm{~h}$ & 8.07 & $\begin{array}{l}426.0 \\
(421.7 ; 430.3)\end{array}$ & $\begin{array}{l}-0.3 \\
(-3.1 ; 2.4)\end{array}$ & $\begin{array}{l}-2.0 \\
(-4.65 ; 0.65)\end{array}$ \\
\hline$n=72$ & $2 \mathrm{~h} 45 \mathrm{~min}$ & 6.98 & $\begin{array}{l}430.8 \\
(426.4 ; 435.1)\end{array}$ & $\begin{array}{l}4.0 \\
(1.3 ; 6.6)\end{array}$ & $\begin{array}{l}-0.1 \\
(-2.66 ; 2.50)\end{array}$ \\
\hline$n=72$ & $4 \mathrm{~h}$ & 1.70 & $\begin{array}{l}439.1 \\
(435.4 ; 442.7)\end{array}$ & $\begin{array}{l}12.5 \\
(9.6 ; 15.4)\end{array}$ & $\begin{array}{l}3.4 \\
(0.07 ; 6.65)\end{array}$ \\
\hline$n=73$ & $6 \mathrm{~h}$ & 0.909 & $\begin{array}{l}439.0 \\
(435.3 ; 442.7)\end{array}$ & $\begin{array}{l}12.4 \\
(9.8 ; 15.0)\end{array}$ & $\begin{array}{l}3.2 \\
(0.56 ; 5.92)\end{array}$ \\
\hline$n=73$ & $8 \mathrm{~h}$ & 0.690 & $\begin{array}{l}435.9 \\
(432.0 ; 439.8)\end{array}$ & $\begin{array}{l}9.3 \\
(6.7 ; 11.9)\end{array}$ & $\begin{array}{l}2.6 \\
(-0.38 ; 5.63)\end{array}$ \\
\hline$n=73$ & $24 \mathrm{~h}$ & 0.443 & $\begin{array}{l}425.1 \\
(420.8 ; 429.4)\end{array}$ & $\begin{array}{l}-1.5 \\
(-4.7 ; 1.7)\end{array}$ & $\begin{array}{l}-1.6 \\
(-4.83 ; 1.72)\end{array}$ \\
\hline
\end{tabular}

Sample sizes provided in the table refer to the QTcB results. The descriptive statistical analyses of the trabectedin concentrations included $67-73$ patients at each time point

$C F B$ change from base line, $C I$ confidence interval, $m s$ milliseconds

Smaller $\Delta \mathrm{QTcF}$ and comparable $\Delta \mathrm{QTcB}$ values were observed following trabectedin administration, relative to placebo, at the majority of the corresponding time points after dosing (Tables 2,3). The mean $\Delta \mathrm{QTcF}$ ranged from $1.7 \mathrm{~ms}$ to $9.7 \mathrm{~ms}$ after placebo administration on day 1 and from $-6.2 \mathrm{~ms}$ to $3.8 \mathrm{~ms}$ after trabectedin administration on day 2 (Table 2). The mean $\Delta \mathrm{QTcB}$ ranged from $-1.2 \mathrm{~ms}$ to $9.2 \mathrm{~ms}$ after placebo administration on day 1 and from $-2.6 \mathrm{~ms}$ to $12.5 \mathrm{~ms}$ after trabectedin administration on day 2 (Table 3 ).

The QTcF and QTcB interval placebo-adjusted changes from baseline in least square means and the corresponding
90\% CIs are summarized in Tables 2, 3, and Fig. 1. The upper limits of the $90 \% \mathrm{CI}$ for all mean $\Delta \Delta \mathrm{QTcF}$ and $\Delta \Delta \mathrm{QTcB}$ values were $\leq 6.65 \mathrm{~ms}$ at all time points, indicating non-inferiority of trabectedin to placebo with respect to QTc prolongation.

Categorical analyses revealed no patient with an absolute postdose QTcF or QTcB value $>500 \mathrm{~ms}$ after treatment with trabectedin or placebo. No patient and 2 patients $(3 \%)$ exhibited a QTcF and QTcB $>480 \mathrm{~ms}$, respectively, following treatment with trabectedin. No patient and 1 patient (1\%) had a QTcF and QTcB > $480 \mathrm{~ms}$, respectively, after placebo. Four patients (5\%) and 23 patients (31\%) exhibited 


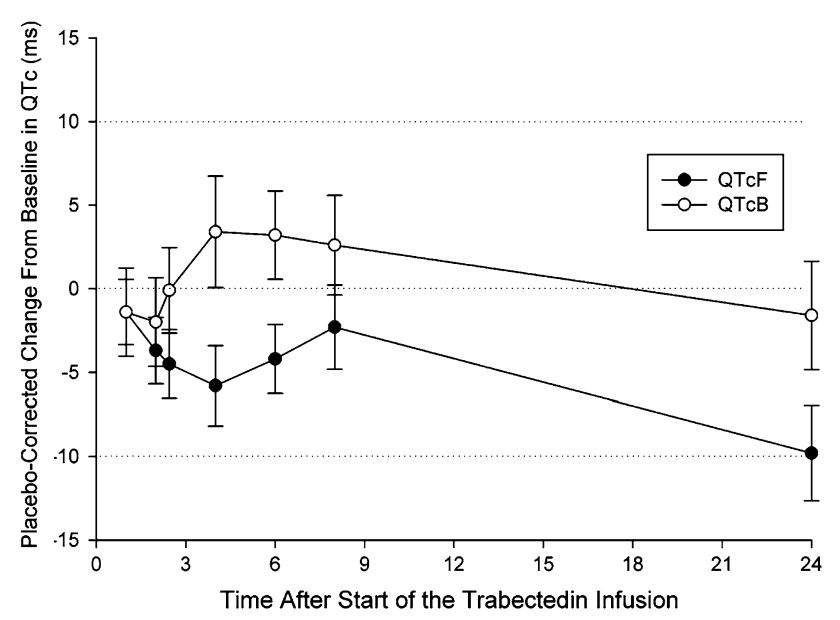

Fig. 1 Placebo-adjusted least square mean $( \pm 90 \%$ confidence interval) change from baseline in QTc $(\Delta \Delta \mathrm{QTc})$ intervals following treatment with a single dose of trabectedin $1.3 \mathrm{mg} / \mathrm{m}^{2}$ (3-h infusion) in patients with advanced solid tumor malignancies

a QTcF and QTcB $>450 \mathrm{~ms}$, respectively, following treatment with trabectedin. Six patients $(8 \%)$ and 21 patients (28\%) had a QTcF and QTcB > $450 \mathrm{~ms}$, respectively, after placebo. No patient exhibited an increase in the QTcF or QTcB from baseline $>60 \mathrm{~ms}$. Two patients $(3 \%)$ and 6 patients $(8 \%)$ had increase in QTcF and QTcB $>30 \mathrm{~ms}$, respectively, following treatment with trabectedin. Two patients (3\%) and 4 patients (5\%) exhibited an increase in $\mathrm{QTcF}$ and QTcB $>30 \mathrm{~ms}$, respectively, after placebo.

Additional categorical analyses indicated that no patient had a QTcF and QTcB value of $<320 \mathrm{~ms}$. QTcF was $<360$ $\mathrm{ms}$ in 1 patient in association with trabectedin and 1 patient with placebo. In addition, no patient had a decrease from baseline in QTcF or QTcB $>60 \mathrm{~ms}$. Three patients (4\%) and 4 patients $(5 \%)$ had a decrease in QTcF and QTcB $>30 \mathrm{~ms}$, respectively, following treatment with trabectedin. No patient and 1 patient (1\%) exhibited a decrease in $\mathrm{QTcF}$ and $\mathrm{QTcB}>30 \mathrm{~ms}$, respectively, after placebo.

Heart rate, T- and U-wave morphology, and PR and QRS intervals

The mean (SD) baseline (predose) HR prior to placebo (day 1) and trabectedin (day 2) administration was 81.2 (12.9) bpm and 76.9 (10.5) bpm, respectively. Mean HR values after both i.v. infusions ranged from 76.9-86.0 bpm for placebo and 73.8-90.0 bpm for trabectedin. At $24 \mathrm{~h}$ after trabectedin infusion, the mean HR declined to a value similar to baseline value prior to placebo infusion (82.6 [11.1] bpm).

The T-wave morphology was unaltered with trabectedin treatment, and no pathological U-wave morphology was observed in this study. The PR and QRS intervals were also not affected by trabectedin.

Plasma pharmacokinetics of trabectedin

Plasma samples were available for bioanalysis from a majority of the enrolled patients (Tables 2 and 3). The concentration of trabectedin was below the limit of quantification for all plasma samples collected at $2 \mathrm{~h} 45 \mathrm{~min}$ after start of placebo infusion (day 1). The mean concentrations increased over the course of the i.v. infusion administered on day 2. Maximum concentrations were observed at an average (SD) of $2.22(0.65) \mathrm{h}$ after the start of the trabectedin infusion. The mean (SD) $C_{\max }$ value was $9.24(3.75) \mathrm{ng} / \mathrm{ml}$. The trabectedin concentrations initially declined rapidly upon completion of the infusion, followed by a protracted decrease in the concentrations, with much lower concentrations observed at the 24-h time point.

Relationship between plasma trabectedin and QT/QTc interval changes

The individual $\Delta \Delta \mathrm{QTc}$ intervals and corresponding trabectedin plasma concentrations exhibited a very weak linear relationship (Fig. 2). For both analyses, the range of $\Delta \Delta$ QTc was quite wide as evidenced by the spread of the data around the regression line. At the mean $C_{\max }$ of $9.2 \mathrm{ng} /$ $\mathrm{ml}$ in plasma, the mean $(90 \% \mathrm{CI}) \Delta \Delta \mathrm{QTcF}$ was $-2.53 \mathrm{~ms}$ $(-4.59,-0.46 \mathrm{~ms})$ and $\Delta \Delta \mathrm{QTcB}$ was $-0.68 \mathrm{~ms}(-3.26$, $1.90 \mathrm{~ms})$.

Safety

Seventy-one (95\%) of the 75 patients in the study experienced TEAEs (Table 4). The most frequent adverse events were nausea $(n=41[55 \%])$, vomiting $(n=39[52 \%])$, abnormal hepatic function ( $n=24[32 \%])$, asthenia $(n=20$ [27\%]), anorexia $(n=15[20 \%])$, fatigue $(n=12[16 \%])$, and neutropenia $(n=12[16 \%])$ (Table 4$)$. Three patients died within 30 days after study treatment. One patient with oropharyngeal cancer died 12 days after receiving study drug, due to progressive disease. The second patient experienced serious grade 3 asthenia and grade 3 vomiting, 5 days after receiving study drug, and died the next day. It was unknown whether these events caused the sudden death. The third patient with linitis plastica died due to euthanasia administered 30 days after study drug at the request of the patient, due to progressive disease. There were no clinically noteworthy changes observed in laboratory assessments, vital signs, ECGs, and physical examination in the study. No patient experienced cardiac toxicity in this study. 


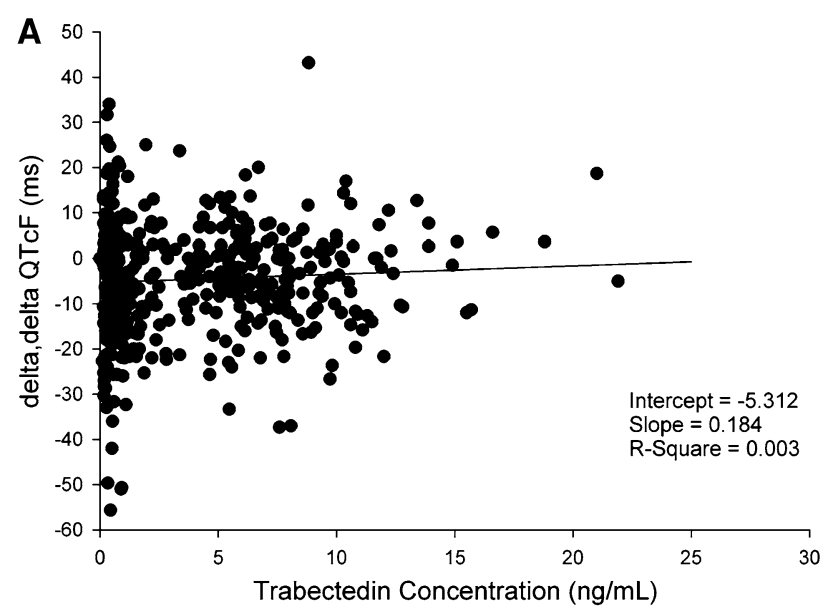

Table 4 Summary of treatment-emergent adverse events by body system or organ class and dictionary derived term (treated analysis set)

\begin{tabular}{lc}
\hline MedDRA preferred term & $\begin{array}{l}\text { Total }(N=75) \\
n(\%)\end{array}$ \\
\hline $\begin{array}{l}\text { Total number of patients with } \\
\text { treatment-emergent adverse events }\end{array}$ & $71(95)$ \\
Nausea & $41(55)$ \\
Vomiting & $39(52)$ \\
Hepatic function abnormal & $24(32)$ \\
Asthenia & $20(27)$ \\
Anorexia & $15(20)$ \\
Neutropenia & $12(16)$ \\
Fatigue & $12(16)$ \\
Constipation & $7(9)$ \\
Anemia & $7(9)$ \\
Cough & $6(8)$ \\
Enzyme abnormality & $5(7)$ \\
Leucopenia & $5(7)$ \\
Dizziness & $5(7)$ \\
Myalgia & $4(5)$ \\
Pyrexia & $4(5)$ \\
Pain & $4(5)$ \\
\hline
\end{tabular}

The most common (i.e., $\geq 5 \%$ ) treatment-emergent adverse events provided

MedDRA Medical dictionary for regulatory activities

$\left(10^{-5} \mathrm{M}\right.$ or $\left.7,620 \mathrm{ng} / \mathrm{ml}\right)$, only a marginal effect (approximately $10 \%$ reduction relative to solvent control) was observed. The effect of a single 1-h i.v. infusion of trabectedin $90 \mu \mathrm{g} / \mathrm{kg}\left(1,080 \mu \mathrm{g} / \mathrm{m}^{2}\right)$ was also investigated in anesthetized cynomolgus monkeys. Relevant effects on heart rate, ECG variables (PR, QT, QTcF and QTcV intervals, and QRS duration), ECG gross morphology and rhythm, left ventricular variables, cardiac output, stroke volume, or respiratory variables were not observed.

In clinical trials, trabectedin was found to be efficacious Considerable evidence is available demonstrating that some non-cardiac (i.e., non-antiarrythmic) drugs delay cardiac repolarization. This effect can be measured by ECG and identified by prolongation of the QT/QTc interval [7, 8]. Prolongation of the QT/QTc interval has been associated with the increased susceptibility to arrhythmias, such as the relatively rare event known as torsades de pointes [8]. Thus, premarketing investigation of the safety of a new pharmaceutical agent typically includes rigorous characterization of its effects on the QT/QTc interval $[9,10]$.

In unpublished nonclinical experiments, trabectedin showed low potential to delay ventricular repolarization. In hERG-transfected HEK293 cells, trabectedin at a concentration of $10^{-8} \mathrm{M}$ to $3 \times 10^{-6} \mathrm{M}$ (approximately $7.6-2,286 \mathrm{ng} / \mathrm{ml}$ ) had no significant effect on the membrane $\mathrm{K}+$ current (IKr). However, at a high concentration and well tolerated in the treatment of several tumor types including ovarian cancer $\left(1.3 \mathrm{mg} / \mathrm{m}^{2}, 3\right.$-h i.v. infusion every 3 weeks $)$, breast cancer $\left(0.58 \mathrm{mg} / \mathrm{m}^{2}\right.$, weekly and $1.3 \mathrm{mg} / \mathrm{m}^{2}$ every 3 weeks), and soft tissue sarcoma ( $1.5 \mathrm{mg} /$ $\mathrm{m}^{2}$, 24-h i.v. infusion once every 3 week) [11-15]. Although higher doses have been administered to sarcoma cancer patients, the $3-\mathrm{h}$ infusion of $1.3 \mathrm{mg} / \mathrm{m}^{2}$ used in this study produced concentrations in plasma that are higher than those following infusions of longer duration (e.g., $1.14 \mathrm{ng} / \mathrm{ml}$ following $1.5 \mathrm{mg} / \mathrm{m}^{2}$ given as a 24 -h i.v. infusion) [16].

The present study was designed to determine as precisely as possible the effects of trabectedin on QTc. The design included a number of characteristics considered to be important for the systematic evaluation of a drug's effect 
on QTc interval prolongation and proarrhythmic potential in humans (i.e., "thorough QT/QTc study") [17]. It included digital ECG data collection in triplicate with rigorous methodology, ECG review by experts, application of appropriate heart rate corrections of measured QT interval, analysis of central tendency and categorical analysis, and characterization of the concentration-effect relationship by simultaneous measurement of trabectedin concentrations in plasma and QTc intervals. Consistent with guidelines, the criterion for a negative study was determined a priori if the upper bound of the $90 \%$ two-sided CI for the largest timematched mean effect on the QTc excluded $10 \mathrm{~ms}$.

The conventional design of the "thorough QT/QTc" includes administration of substantial multiples of the dose of a test drug to normal healthy volunteers who are not concomitantly taking other medications. These features increase the likelihood of observing QTc prolongation if the test drug exhibits this property. Due to safety and tolerability concerns, patients with advanced malignancies were enrolled in the present study and were administered a therapeutic dose $\left(1.3 \mathrm{mg} / \mathrm{m}^{2}\right)$ of trabectedin. All patients received an i.v. infusion of placebo (i.e., saline) followed by trabectedin in a fixed sequence. The crossover design element allowed patients to be their own control. Random assignment to this sequence versus the reverse order (i.e., trabectedin followed by placebo), as recommended in $\mathrm{ICH}$ E14, was neither practical nor ethical since the terminal $t_{1 / 2}$ of trabectedin is approximately $180 \mathrm{~h}$ [4] and would have required a protracted washout between the treatment days. As a consequence, only the patients were blinded to the order of treatments, whereas the investigator and clinical site personnel were unblinded. The consequences of the single-blind nature of the study are likely to be small, since the ECGs were analyzed by independent reviewers who were blinded to treatment (i.e., study day) and time.

The standard "thorough QT/QTc" study includes a positive control, which demonstrates an ability to detect clinically significant prolongation in the QTc interval. It has been customary to administer patients a single $400 \mathrm{mg}$ oral dose of moxifloxacin [18-22]. Due to ethical constraints and practical considerations, the administration of moxifloxacin to the patients enrolled in the present study was not possible. "Thorough QT/QTc" studies also often include a full-day baseline correction method (to account for certain uncontrollable factors such as circadian variation, food effects, etc) where triplicate ECGs at time-matched points are collected on the day before the test drug and placebo are given. However, recent work has provided evidence that this may not be necessary [23]. With the study design utilized in this present study, where each patient was his or her own control, predose baseline is considered to be sufficient, as the difference in $\Delta Q T c$ between drug and placebo for each patient effectively accounts for diurnal variation and other factors that are difficult or not possible to control.

Trabectedin did not prolong QT/QTc intervals relative to placebo, in this study. The upper limits of the $90 \%$ CI for all mean $\Delta \Delta \mathrm{QTcF}$ and $\Delta \Delta \mathrm{QTcB}$ values were $\leq 6.65 \mathrm{~ms}$ at all time points indicating non-inferiority of trabectedin to placebo. Further, no patient had a QTcF or QTcB value that was $>500 \mathrm{~ms}$, a time-matched increase in QTc from baseline $>60 \mathrm{~ms}$ in either treatment at any time point, nor a QTc that was less than $350 \mathrm{~ms}$. Moreover, there were no reports of sudden death or ventricular arrhythmias, including ventricular fibrillation.

There was a modest increase in mean heart rate observed with trabectedin relative to placebo at $4 \mathrm{~h}$ after the start of infusion and throughout most of the 24-h observation period. At $24 \mathrm{~h}$ after trabectedin infusion, the mean heart rate values were similar to baseline values before placebo infusion. The increase in heart rate with trabectedin was of no clinical significance. Rare and sporadic out of range values were noted for other 12-lead ECG parameters (heart rate, PR interval, QRS interval, T-wave and U-wave morphology). However, no consistent or particular association to any treatment (trabectedin or placebo) was observed.

The safety profile following administration of a single therapeutic dose of trabectedin $\left(1.3 \mathrm{mg} / \mathrm{m}^{2}\right)$ was similar to that reported in previous clinical studies. The most commonly reported adverse events were asthenia, abnormal hepatic function, and vomiting that are consistent with the known safety profile of trabectedin. No adverse events suggestive of proarrhythmic potential were observed.

In conclusion, trabectedin at a therapeutic dose of $1.3 \mathrm{mg} / \mathrm{m}^{2}$ administered as a 3 -h i.v. infusion did not prolong the QTc interval in patients with advanced solid tumor malignancies in comparison with placebo. Further, the safety profile was consistent with previous studies, indicating trabectedin was well tolerated.

Acknowledgments The authors thank the following investigators who participated in this study: Belgium: Jan B. Vermorken; Luc Dirix; Machiels Jean-Pascal; France: Axel Le Cesne; Jean-Yves Blay; India: Govind K. Babu; Minish M. Jain; Korea: Do-Youn, Oh; Hyun Cheol Chung; Joo-Hyun Nam; Keunchil Park; Russia: George Manikhas; Mikhail Y. Biakhov; Sergei A. Tjulandin; Vladimir F. Semiglazov; Spain: Emiliano Calvo; United States: Lorrin Kwock-Chong Yee; Arthur P. Staddon; Raymond Thertulien; Margaret von Mehren. The authors also thank the Cardiovascular Safety Group at Johnson \& Johnson Pharmaceutical Research \& Development for data interpretation; Tom Verheaghe (Johnson \& Johnson Pharmaceutical Research \& Development; Division of Janssen Pharmaceutica N.V., Beerse, Belgium) for coordinating the analysis of the trabectedin concentrations in plasma samples; and Holly Adams (Johnson \& Johnson Pharmaceutical Research \& Development) for preparing the descriptive statistical analyses of trabectedin concentration-time data. Ananya Chikramane 
(SIRO Clinpharm Pvt. Ltd.) provided writing assistance, and Namit Ghildyal (Johnson \& Johnson Pharmaceutical Research \& Development, L.L.C.) provided additional editorial assistance. This study was funded by Johnson \& Johnson Pharmaceutical Research \& Development, LLC. The sponsor also provided a formal review of this manuscript.

Conflict of interest Drs. Thertulien, Manikhas, Dirix, Jain and Staddon have no conflict of interest. Dr. Vermorken has delivered lectures for PharmaMar S.A. and Johnson \& Johnson. Dr. Park is an advisor to Astra Zeneca, Boehringer Ingelheim, Eli Lilly, Pfizer, Roche and is on the Speaker's Bureau of Astra Zeneca, Eli Lilly and Roche. Drs. Zannikos, Parekh, Natarajan and Jiao are employees of Johnson \& Johnson Pharmaceutical Research \& Development, L.L.C. All authors met ICMJE criteria and all those who fulfilled those criteria are listed as authors. All authors had access to the study data, made the final decision about where to publish these data, and approved submission to the journal.

Open Access This article is distributed under the terms of the Creative Commons Attribution Noncommercial License which permits any noncommercial use, distribution, and reproduction in any medium, provided the original author(s) and source are credited.

\section{References}

1. Boudou L, Baconnier M, Blay J-Y, Lombard-Bohas C, Cassier PA (2009) Trabectedin for the management of soft-tissue sarcoma. Expert Rev Anticancer Ther 9:727-737

2. Carter NJ, Keam SJ (2007) Trabectedin: a review of its use in the management of soft tissue sarcoma and ovarian cancer. Drugs 67:2257-2276

3. EMEA Yondelis (2010) Summary of Product Characteristics. http://www.ema.europa.eu/docs/en_GB/document_library/EPAR Product_Information/human/000773/WC500045832.pdf. Accessed 27 Aug 2010

4. Perez-Ruixo JJ, Zannikos P, Hirankarn S, Stuyckens K, Ludwig EA, Soto-Matos A, Lopez-Lazaro L, Owen JS (2007) Population pharmacokinetic meta-analysis of trabectedin (ET-743, Yondelis) in cancer patients. Clin Pharmacokinet 46:867-884

5. Beumer JH, Lopez-Lazaro L, Schellens JH, Beijnen JH, van Tellingen O (2009) Evaluation of human plasma protein binding of trabectedin (Yondelis, ET-743). Curr Clin Pharmacol 4:38-42

6. Vermeir M, Hemeryck A, Cuyckens F, Francesch A, Bockx M, Van Houdt J, Steemans K, Mannens G, Aviles P, De Coster R (2009) In vitro studies on the metabolism of trabectedin (YONDELIS) in monkey and man, including human CYP reaction phenotyping. Biochem Pharmacol 77:1642-1654

7. Gussak I, Litwin J, Kleiman R, Grisanti S, Morganroth J (2004) Drug-induced cardiac toxicity: emphasizing the role of electrocardiography in clinical research and drug development. J Electrocardiol 37:19-24

8. Roden M (2004) Drug induced prolongation of the QT interval. N Engl J Med 350:1013-1022

9. Shah RR (2002) The significance of QT interval in drug development. Br J Clin Pharmacol 54:188-202

10. Darpo B, Nebout T, Sager PT (2006) Clinical evaluation of QT/ QTc prolongation and proarrhythmic potential for nonantiarrhythmic drugs: the international conference on harmonization of technical requirements for registration of pharmaceuticals for human use E14 guideline. J Clin Pharmacol 46:498-507
11. Cassier PA, Dufresne A, Blay JY, Fayette J (2008) Trabectedin and its potential in the treatment of soft tissue sarcoma. Ther Clin Risk Manag 4:109-116

12. Sessa C, De Braud F, Perotti A, Bauer J, Curigliano G, Noberasco C, Zanaboni F, Gianni L, Marsoni S, Jimeno J, D'Incalci M, Dall'o E, Colombo N (2005) Trabectedin for women with ovarian carcinoma after treatment with platinum and taxanes fails. J Clin Oncol 23:1867-1874

13. Demetri GD, Chawla SP, von Mehren M, Ritch P, Baker LH, Blay JY, Hande KR, Keohan ML, Samuels BL, Schuetze S, Lebedinsky C, Elsayed YA, Izquierdo MA, Gomez J, Park YC, Le Cesne A (2009) Efficacy and safety of trabectedin in patients with advanced or metastatic liposarcoma or leiomyosarcoma after failure of prior anthracyclines and ifosfamide: results of a randomized phase II study of two different schedules. J Clin Oncol 27:4188-4196

14. Gurtler S, Goldstein L, Delprete S (2005) Trabectedin in third line breast cancer: a multicenter, randomized, phase II study comparing two administration. J Clin Oncol 23:625

15. Monk BJ, Herzog TJ, Kaye SB, Krasner CN, Vermorken JB, Muggia FM, Pujade-Lauraine E, Lisyanskaya AS, Makhson AN, Rolski J, Gorbounova VA, Ghatage P, Bidzinski M, Shen K, Ngan HY, Vergote IB, Nam JH, Park YC, Lebedinsky CA, Poveda AM (2010) Trabectedin plus pegylated liposomal doxorubicin in recurrent ovarian cancer. J Clin Oncol 28:3107-3114

16. Puchalski TA, Ryan DP, Garcia-Carbonero R, Demetri GD, Butkiewicz L, Harmon D, Seiden MV, Maki RG, Lopez-Lazaro L, Jimeno J, Guzman C, Supko JG (2002) Pharmacokinetics of ecteinascidin 743 administered as a $24 \mathrm{~h}$ continuous intravenous infusion to adult patients with soft tissue sarcomas: associations with clinical characteristics, pathophysiological variables and toxicity. Cancer Chemother Pharmacol 50:309-319

17. International Conference on Harmonization of Technical Requirements for Registration of Pharmaceuticals for Human Use (2005) The clinical evaluation of QT/QTc interval prolongation and proarrhythmic potential for non-antiarrhythmic drugs: E14. Geneva, Switzerland (updated 12 May 2005). Available from: http:// www.ich.org/LOB/media/MEDIA1476.pdf

18. Bloomfield DM, Kost JT, Ghosh K, Hreniuk D, Hickey LA, Guitierrez MJ, Gottesdiener K, Wagner JA (2008) The effect of moxifloxacin on QTc and implications for the design of thorough QT studies. Clin Pharmacol Ther 84:475-480

19. Malik M, Hnatkova K, Schmidt A, Smetana P (2009) Electrocardiographic QTc changes due to moxifloxacin infusion. J Clin Pharmacol 49:674-683

20. Iwamoto M, Kost JT, Mistry GC, Wenning LA, Breidinger SA, Marbury TC, Stone JA, Gottesdiener KM, Bloomfield DM, Wagner JA (2008) Raltegravir thorough QT/QTc study: a single supratherapeutic dose of raltegravir does not prolong the QTcF interval. J Clin Pharmacol 48:726-733

21. Hulhoven R, Rosillon D, Letiexhe M, Meeus MA, Daoust A, Stockis A (2007) Levocetirizine does not prolong the QT/QTc interval in healthy subjects: results from a thorough QT study. Eur J Clin Pharmacol 63:1011-1017

22. Bloomfield DM, Krishna R, Hreniuk D, Hickey L, Ghosh K, Bergman AJ, Miller J, Gutierrez MJ, Stoltz R, Gottesdiener KM, Herman GA, Wagner JA (2009) A thorough QTc study to assess the effect of sitagliptin, a DPP4 inhibitor, on ventricular repolarization in healthy subjects. J Clin Pharmacol 49:937-946

23. Zhang X, Silkey M, Schumacher M, Wang L, Raval H, Caulfield JP (2009) Period correction of the QTc of moxifloxacin with multiple predose baseline ECGs is the least variable of 4 methods tested. J Clin Pharmacol 49:534-539 